View Article Online / Journal Homepage / Table of Contents for this issue

YOUNG : C-PHENYT,S-TRIAZOLE.

\title{
LXII._C-Phenyi-s-triazole.
}

By George Youna.

IN a previous communication, in conjunction with Mr. Oates (Trans., $1901,79,665)$, I described the preparation of 3-phenyl-1-methyl-5hydroxy-1:2:4-triazole, $\stackrel{\mathrm{N} \cdot \mathrm{NMe}}{\mathrm{C} \mathrm{Ph} \cdot \mathrm{N}} \geqslant \mathrm{C} \cdot \mathrm{OH}$, and, on heating this substance with phosphorus pentasulphide, a product was obtained, the empirical formula for which contained $\mathrm{CH}_{2}$ less than that required for 3-phenyl1-methyl-s-triazole. As this was in agreement with the experience of Andreocci (Atti R. Accad. Lincei, 1890, [iv], 6, ii, 209), who obtained 1-phenyl-3-methyl-1 : $2: 4$-triazole, $\stackrel{\underset{\mathrm{N}}{\mathrm{N}} \mathrm{P}: \mathrm{N}: \mathrm{N}}{\mathrm{N}}>\mathrm{C} \cdot \mathrm{Me}$, by heating 1-phenyl-3 : 4-dimethyl-5-oxy-4 : 5-dihydro-1 : $2:$ 4-triazole,<smiles></smiles>

witk phosphorus pentasulphide, we ascribed to our product the constitution of $C$-phenyl-s.triazole, $\underset{\mathrm{CPh} \cdot \mathrm{N}}{\mathrm{N}-\mathrm{NH}} \geqslant \mathrm{CH}$. This view of the 
constitution is now confirmed, as the product obtained on heating $C$-phenylhydroxy-s-triazole, $\stackrel{\mathrm{N}-\mathrm{NH}}{\mathrm{C} \mathrm{Hh} \cdot \mathrm{N}} \geqslant \mathrm{C} \cdot \mathrm{OH}$ (Young and Witham, Trans., 1900, 77, 226), with pentasulphide is found to be identical with the substance obtained from 3-phenyl-1-methyl-5-hydroxy-1:2:4triazole.

The term $s$-triazole is used in this paper to distinguish the triazole,

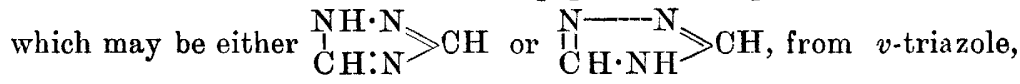
which may be $\stackrel{\mathrm{NH} \cdot \mathrm{N}}{\mathrm{N}: \mathrm{CH}}>\mathrm{CH}$ or $\underset{\mathrm{N}}{\mathrm{N}}-\mathrm{NH}$

It is worth noting that, whereas the melting point of 1-phenyl1:2:4-triazole, $\begin{aligned} & \mathrm{N} P h \cdot \mathrm{N}_{\mathrm{N}} \\ & \mathrm{CH}: \mathrm{N}\end{aligned}>\mathrm{CH}$ (m. p. $47^{\circ} ;$ Andreocci, Ber., 1892, 25, 225 ), follows Wedekind's rule (Ber., 1898, 31,949) for the effect of substitution on the melting points of carbon-nitrogen cyclic compounds, both $C$-phenyl-s-triazole, $\underset{\mathrm{CPh} \cdot \mathrm{N}}{\mathrm{N}-\mathrm{NH}}>\mathrm{CH}$ (m. p. $119 \cdot 5-120^{\circ}$; this paper), and 1-phenyl-1:3:4-triazole, $\mathrm{CH}_{\mathrm{CH} \cdot \mathrm{NPh}}^{\mathrm{N}}>\mathrm{CH}\left(\mathrm{m} . \mathrm{p} .121^{\circ}\right.$; Pellizzari and Massa, Atti R. Accad. Lincei, 1901, [v ], 10, i, 363), melt at almost the same temperature as the parent substance, $s$-triazole (m. p. 120-121 $1^{\circ}$; Andreocci, loc. cit.).

\section{EXPERIMENTA L.}

$C$-Phenylhydroxy-s-triazole (6 grams) was intimately mixed with phosphorus pentasulphide ( 15 grams) and the mixture heated in an oil-bath for 6 hours at $230-250^{\circ}$. The product was boiled with aqueous potassium carbonate in a reflux apparatus, and, after cooling, was extracted repeatedly with ether. The ethereal solution was then concentrated until crystallisation commenced, when, on cooling, the residual liquid crystallised to a mass of shining plates and needles, which melted at $119-120^{\circ}$.

$0 \cdot 1825$ gave $0.4426 \mathrm{CO}_{2}$ and $0.0809 \mathrm{H}_{2} \mathrm{O} . \quad \mathrm{C}=66 \cdot 14 ; \mathrm{H}=4.92$.

$0 \cdot 1740, \quad 43 \cdot 6$ c.c. moist nitrogen at $18^{\circ}$ and $761 \mathrm{~mm}$. $\mathrm{N}=28 \cdot 96$. $\mathrm{C}_{8} \mathrm{H}_{7} \mathrm{~N}_{3}$ requires $\mathrm{C}=66.21: \mathrm{H}=4.83 ; \mathrm{N}=28.97$ per cent.

$C$-Phenyl-s-triazole was readily soluble in alcohol, warm ether, or benzene, and moderately so in hot water, but dissolved only to a slight extent in light petroleum ; it crystallised from water in clusters of soft, matted needles, from a mixture of benzene and light petroleum in nodular aggregates of microscopic needles, and from dilute alcohol in slender needles. It melted at $119.5-120^{\circ}$, volatilised in shining 
plates when heated over its melting point, and was slightly volatile in a current of steam.

A mixture of equal parts of the products obtained from 3-phenyl-1. methyl-5-hydroxy-1:2:4-triazole and from $C$-phenylhydroxy-s-triazole respectively melted at $119-119 \cdot 5^{\circ}$.

Towards aqueous alkali hydroxides and towards silver nitrate, $C$-phenyl-s-triazole exhibited the behaviour characteristic of those triazoles in which the $N$-hydrogen atom is not substituted. It dissolved in dilute aqueous potassium hydroxide more readily than in water, and was reprecipitated from the alkaline solution on addition of ammonium acetate and expulsion of the liberated ammonia by gentle warming. When treated with silver nitrate in alcoholic solution, it formed the additive compound of silver nitrate and the silver derivative, $\mathrm{C}_{5} \mathrm{H}_{6} \mathrm{~N}_{3} \mathrm{Ag}, \mathrm{AgNO}_{3}, \mathrm{H}_{2} \mathrm{O}$, which was obtained as a white precipitate from which $\mathrm{H}_{2} \mathrm{O}$ was driven off at $110^{\circ}$.

0.8184 , at $110^{\circ}$, lost $0.0352 \mathrm{H}_{2} \mathrm{O} . \mathrm{H}_{2} \mathrm{O}=4.30$.

0.8184 gave $0.4024 \mathrm{Ag}$. $\mathrm{Ag}=49 \cdot 17$.

$\mathrm{C}_{8} \mathrm{H}_{6} \mathrm{~N}_{3} \mathrm{Ag}, \mathrm{AgNO}_{3}, \mathrm{H}_{2} \mathrm{O}$ requires $\mathrm{Ag}=49 \cdot 34 ; \mathrm{H}_{2} \mathrm{O}=4 \cdot 11$ per cent.

$C$-Phenyl-s-triazole dissolved readily in cold dilute or in warm concentrated hydrochloric acid. The hydrochloride, which crystallised in slender needles on cooling the solution in the concentrated acid, decomposed on drying or on treatment with water. On adding platinic chloride to the solution in warm concentrated hydrochloric acid and cooling, the platinichloride, $\left(\mathrm{C}_{8} \mathrm{H}_{7} \mathrm{~N}_{3}\right)_{2}, \mathrm{H}_{2} \mathrm{PtCl}_{3}, 3 \mathrm{H}_{2} \mathrm{O}$, separated in yellowish-red plates containing 3 mols. of water of crystallisation, which were driven off at $110^{\circ}$. The anhydrous platinichloride melted and decomposed at $223^{\circ}$.

1.2298 , at $110^{\circ}$, lost $0.0912 \mathrm{H}_{2} \mathrm{O} . \quad \mathrm{H}_{2} \mathrm{O}=7 \cdot 41$.

0.7730 , dried at $110^{\circ}$, gave $0.2138 \mathrm{Pt} . \quad \mathrm{Pt}=27.66$.

$\left(\mathrm{C}_{8} \mathrm{H}_{7} \mathrm{~N}_{3}\right)_{2}, \mathrm{H}_{2} \mathrm{PtCl}_{6}, 3 \mathrm{H}_{2} \mathrm{O}$ requires $\mathrm{H}_{2} \mathrm{O}=7 \cdot 16$ per cent.

$\left(\mathrm{C}_{8} \mathrm{H}_{7} \mathrm{~N}_{3}\right)_{2}, \mathrm{H}_{2} \mathrm{PtCl}_{6} \quad$ " $\quad \mathrm{Pt}=27 \cdot 86 \quad$,

When washed with water, the platinichloride lost 2 mols. of hydrochloric acid and was converted into the derivative,

$$
\left(\mathrm{C}_{8} \mathrm{H}_{7} \mathrm{~N}_{3}\right)_{2}, \mathrm{PtCl}_{4}, 3 \mathrm{H}_{2} \mathrm{O} \text {, }
$$

which is of a lighter yellow colour. This salt lost $3 \mathrm{H}_{2} \mathrm{O}$ at $110^{\circ}$, dissolved in aqueous potassium carbonate, and was precipitated unchanged from this solution on the addition of hydrochloric acid.

0.6007 , at $110^{\circ}$, lost $0.0468 \mathrm{H}_{2} \mathrm{O} . \quad \mathrm{H}_{2} \mathrm{O}=7.79$.

0.5561 , dried at $110^{\circ}$, gave $0.1736 \mathrm{Pt}$. $\mathrm{Pt}=31.22$.

0.5433 , precipitated from aqueous potassium carbonate and dried at $110^{\circ}$, gave $0 \cdot 1699 \mathrm{Pt} . \quad \mathrm{Pt}=31 \cdot 27$.

$\left(\mathrm{C}_{8} \mathrm{H}_{7} \mathrm{~N}_{3}\right)_{2}, \mathrm{PtCl}_{4}, 3 \mathrm{H}_{2} \mathrm{O}$ requires $\mathrm{H}_{2} \mathrm{O}=7.93$ per cent.
$\left(\mathrm{C}_{8} \mathrm{H}_{7} \mathrm{~N}_{3}\right)_{2}, \mathrm{PtCl}_{4}$
n
$\mathrm{Pt}=31 \cdot 10 \quad$, 
The acetyl derivative, $\mathrm{C}_{8} \mathrm{H}_{6} \mathrm{~N}_{3} \cdot \mathrm{O}_{2} \mathrm{H}_{3} \mathrm{O}$, was obtained by boiling $C$-phenyl-s-triazole with acetic anhydride and sodium acetate; it dissolved readily in alcohol, ether, benzene, or warm light petroleum; from its solution in the last solvent, it crystallised in feathery aggregates of slender needles. When recrystallised from dilute alcohol, it formed small, white needles which melted at $90^{\circ}$. It was easily hydrolysed by boiling aqueous potassium carbonate to $C$-phenyl-striazole melting at $119-120^{\circ}$.

0.2242 gave $43 \cdot 2$ c.c. moist nitrogen at $15^{\circ}$ and $754 \mathrm{~mm} . \quad \mathrm{N}=22.38$. $\mathrm{C}_{8} \mathrm{H}_{6} \mathrm{~N}_{3} \cdot \mathrm{C}_{2} \mathrm{H}_{3} \mathrm{O}$ requires $\mathrm{N}=22 \cdot 46$ per cent.

The carbamido-derivative of $C$-phenyl-s-triazole, described in the previous paper (Trans., 1901, 79, 665), was also prepared by the action of potassium cyanate and hydrochloric acid on $C$-phenyl-s-triazole obtained from $C$-phenglhydroxy-s-triazole. After solution in benzene and precipitation by adding light petroleum, it melted at $147^{\circ}$. The analysis shows that it probably contained traces of unchanged phengltriazole. View Article Online

$0 \cdot 1818$ gave $0.3855 \mathrm{CO}_{2}$ and $0.0818 \mathrm{H}_{2} \mathrm{O} . \quad \mathrm{C}=57 \cdot 83 ; \mathrm{H}=4.09$. $\mathrm{C}_{8} \mathrm{H}_{6} \mathrm{~N}_{3} \cdot \mathrm{CO} \cdot \mathrm{NH}_{2}$ requires $\mathrm{C}=57 \cdot 44 ; \mathrm{H}=4 \cdot 25$ per cent.

The carbamido-derivative was easily hydrolysed by boiling water or by cold dilute hydrochloric acid with evolution of carbon dioxide and formation of phenyltriazole, which melted at $119^{\circ}$. 